\title{
Quantitative contrast enhanced dual energy CT to predict avascular necrosis: a feasibility study of proximal humerus fractures
}

Kevin B. Hoover ${ }^{* *} \mathbb{0}$, Alexandria O. Starks², Valentina Robila ${ }^{3}$ and Daniel L. Riddle ${ }^{4}$

\begin{abstract}
Background: Avascular necrosis is a delayed complication of proximal humerus fractures that increases the likelihood of poor clinical outcomes. CT scans are routinely performed to guide proximal humerus fracture management. We hypothesized iodine concentration on post-contrast dual energy CT scans identifies subjects who develop avascular necrosis and ischemia due to compromised blood flow.
\end{abstract}

Materials and methods: 55 patients with proximal humerus fractures enrolled between 2014 and 2017 underwent clinical, radiographic and contrast enhanced dual energy CT assessment. lodine densities of the humeral head and the glenoid (control) were measured on CT. Subjects managed with open reduction internal fixation or conservatively (non-surgical) were followed for up to two years for radiographic evidence of avascular necrosis. Arthroplasty subjects underwent histopathologic evaluation for ischemia of the resected humeral head.

Results: 17 of 55 subjects (30.9\%) were treated conservatively, 21 (38.2\%) underwent open reduction internal fixation and 17 of 55 (30.9\%) underwent arthroplasty. Of the 38 subjects treated conservatively or with ORIF, 20 (52.6\%) completed 12 months of follow up and 14 (36.8\%) 24 months of follow up. At 12 months follow up, two of 20 subjects (10\%) and at 24 months 3 of 14 subjects (21.4\%) developed avascular necrosis. At 12 months, the mean humerus/ glenoid iodine ratio was 1.05 (standard deviation 0.24) in subjects with AVN compared to 0.91 (0.24) in those who did not. At 24 months, subjects with avascular necrosis had a mean humerus/glenoid iodine concentration ratio of 1.06 (0.17) compared to $0.924(0.21)$ in those who did not. Of 17 arthroplasty subjects, 2 had severe ischemia and an iodine ratio of 1.08 (0.30); 5 had focal ischemia and a ratio of $1.00(0.36)$; and 8 no ischemia and a ratio of $0.83(0.08)$.

Conclusions: Quantifying iodine using dual energy $C T$ in subjects with proximal humerus fractures is technically feasible. Preliminary data suggest higher humeral head iodine concentration may increase risk of avascular necrosis; however, future studies must enroll and follow enough subjects managed with open reduction internal fixation or conservatively for two or more years to provide statistically significant results.

Trial Registrations NCT02170545 registered June 23, 2014, ClinicalTrials.gov.

Keywords: Dual energy computed tomography, lodine map, Avascular necrosis, Ischemia, Bone, Fracture

*Correspondence: kevinbhoover@gmail.com

1 Mink Radiology, Cedars-Sinai Health System, 8670 Wilshire Blvd Suite

101, Beverly Hills, CA 90211, USA

Full list of author information is available at the end of the article

\section{Background}

Displaced proximal humerus fractures represent a major challenge for patients and orthopedic surgeons. These fractures are the third most common type of long bone fracture after hip and distal radius fractures with approximately $20 \%$ undergoing surgical treatment [1-3]. One 
of the major fracture complications is avascular necrosis (AVN). This is secondary to impairment of the blood supply to the humeral head. This blood supply is primarily provided by the anterior and posterior circumflex humeral arteries and the anastomotic network between the two [4,5]. The development of AVN is thought to occur in approximately $18 \%$ of displaced proximal humerus fractures within two years of injury. The incidence increases over time and estimates vary from 4 to $75 \%$ [6-9]. AVN may eventually lead to joint destruction with collapse of the articulating surface and is associated with poor patient outcomes [10-12].

Several of the clinical factors associated with humeral head fractures have been studied, but none have been shown to be predictive of future AVN using a prospective study design [13]. Greater fracture displacement and higher number of fracture fragments at the time of injury are associated with AVN $[3,14-16]$. The relative risk of AVN from conservative and surgical treatment with open reduction internal fixation (ORIF) is controversial [13]. Efforts to predict AVN at the time of surgery based on pulsatile flow through surgical burr holes and laser doppler flowmetry have not been successful $[7,17]$.

Radiography and computed tomography (CT) are the current techniques of choice in the diagnosis and management of proximal humerus fractures $[1,3,10]$. Radiography is the first line imaging to assess fracture comminution, fracture displacement and glenohumeral joint dislocation. CT provides a more precise evaluation of fracture anatomy and joint alignment that is used in surgical planning [10]. Magnetic resonance imaging (MRI) is not commonly utilized in the evaluation of humeral head fractures.

MRI studies of femoral neck fractures demonstrate a decrease in contrast enhancement in subjects who developed AVN [18-22]. MRI, specifically dynamic contrast enhanced MRI, has shown promise in the prediction of AVN of the femoral head [18, 20-23]. However, this technique is an expensive, technically demanding and time intensive examination. It requires a high level of expertise to perform that may not be available at the time when patient management decisions are made. Furthermore, MRI is not routinely used in the post-operative setting due to the extensive artifact associated with metal from ORIF and arthroplasty hardware. For these and other reasons, MRI is not routinely used in either the surgical planning or the post-operative follow up of proximal humerus fractures.

In addition to the precise anatomic information available with $\mathrm{CT}$, utilization of two kilovoltages, or dual energy (DECT), can be used to evaluate for gout, bone marrow edema and tissue perfusion [24-28]. DECT is a long-standing technology that has recently been commercialized and can distinguish different materials based on their X-ray attenuation at different voltages $[26,29,30]$. It can be used to distinguish trabecular bone from marrow constituents such as fat and collagen, calcium from iodinated contrast, different types of iodinated contrast and calcifications [25, 31-34]. This has led to an important clinical application: the virtual noncontrast reconstruction that removes iodinated contrast from contrast enhanced DECT images to distinguish contrast enhancement from calcium and blood. It also decreases the total radiation dosage to patients by eliminating the need for pre-contrast imaging $[25,26]$. A contrast only reconstruction can be used to quantify the amount of iodine from intravenous contrast as a measure of tissue perfusion (i.e. iodine overlay or "iodine map") [27, 30, 35]. Iodine maps have been primarily used to evaluate tumor vascularity before and after chemotherapy treatment $[36,37]$. The use of DECT to measure blood perfusion of bone remains largely unexplored.

We hypothesized the quantity of iodine in the humeral head after intravenous contrast injection measured with DECT represents a surrogate marker of bone perfusion. Like the decrease in femoral head enhancement seen on MRI of femoral neck fractures, we hypothesized there would be decreased perfusion and iodine concentration in the humeral heads of subjects who have histopathologic evidence of ischemia and later develop radiographic evidence of AVN. To evaluate this hypothesis, we conducted a prognostic, prospective feasibility cohort study to measure the iodine concentration in the humeral head after fracture using iodine maps. Feasibility studies address areas that may impact the completion of a larger clinical study, including process, resources, management and scientific [38]. The purposes of our study were to determine: (1) if we could successfully recruit and retain subjects with proximal humerus fractures and follow those treated conservatively or with ORIF for two-years (process); (2) if we could identify subjects with histopathologic evidence of ischemia or radiographic evidence of AVN (scientific); (3) if iodine concentration measurements could be routinely obtained on study subjects (scientific); and (4) if there is preliminary evidence of iodine concentration differences in subjects with histopathologic evidence of ischemia or radiographic evidence of AVN (scientific).

\section{Methods \\ Study design}

This HIPAA compliant, prognostic, prospective feasibility cohort study of a newly proposed diagnostic test for quantifying AVN risk following proximal humerus fracture. was approved by the Institutional Review Board (IRB) at Virginia Commonwealth University. 
Patients 18 years and older with proximal humerus fractures were recruited during orthopedic inpatient consultations or office visits. Patients were excluded based on the following criteria: contralateral humerus AVN; history of iodinated intravenous (IV) contrast allergy with anaphylaxis; multiple myeloma due to additional risk of contrast induced kidney damage; sickle cell disease due to the pre-existing risk of AVN; pregnancy due to the risk of radiation to the fetus; and pre-existing renal insufficiency due to the additional risk of contrast induced nephropathy.

After signing an IRB approved consent form, enrolled subjects underwent a routine clinical evaluation, which includes a CT scan at our institution. Instead of a conventional CT scan using a single source and $k V p$, DECT of the affected shoulder was performed (see below). The subsequent clinical management was based on institutional usual care criteria such as clinical exam, radiographs and $\mathrm{CT}$. While the surgeon was able to see the standard anatomic information provided by the CT scan, they were blinded to the quantitative data acquired from DECT (see below). As per clinical protocol, subjects were managed one of three ways: without surgical intervention (conservatively), with ORIF or by arthroplasty. Conservative management routinely utilized sling immobilization for two weeks followed by physical therapy. ORIF utilized a locked plate and screw construct with or without additional lag screws. Arthroplasty treatment utilized primarily anatomic components, but reverse arthroplasty components were also sometimes used depending on surgeon judgement and experience. Subjects were followed for a total of two years. This included a routine two-week postoperative visit and clinical visits every six months from the date of treatment plan (i.e., 6 months, 12 months, 18 months, and 24 months) that included proximal humerus radiographs to evaluate fracture union. Subjects received text and/or phone visit reminders prior to their scheduled appointment as all clinical patients receive at our institution. Subjects who did not attend scheduled follow up visits received follow up phone calls from clinic and study staff (KBH, AOS). Patient loss to follow up, or attrition, was registered by when it occurred in the six month cycle of appointments [39].

\section{Imaging}

Radiographic evaluation of the fractured humerus included a minimum of two frontal views, with the humerus in internal and external rotation, and a lateral, scapular Y-view. A contrast enhanced DECT was also obtained prior to treatment using the dual source stellar detector Somatom Definition Flash (Siemens Healthcare) (Table 1). Delayed phase imaging was utilized. This was based on prior studies demonstrating bone enhancement and less enhancement variability than other phases [40, 41]. The anatomic CT data were used by all physicians managing the care of the study subjects. The source data were sent for post-processing analysis to Syngo.via (Siemens Healthcare).

The liver virtual noncontrast application of the Syngo. Via was used to generate an iodine map to measure iodine concentration $(\mathrm{mg} / \mathrm{ml})$. Three areas of at least 1 $\mathrm{cm}^{2}$ were hand-drawn in three orthogonal planes (i.e., axial, paracoronal, parasagittal) within the subarticular trabecular bone of the humeral head by a radiologist with 12 year of subspecialized musculoskeletal radiology experience $(\mathrm{KBH})$. The densities within these three areas were averaged to generate the humerus iodine concentration. Similarly, the iodine concentration of an area of at least $1 \mathrm{~cm}^{2}$ within the trabecular bone of the glenoid of the scapula (i.e., the glenoid vault), was measured in the three orthogonal planes and the densities averaged. The iodine concentration data were not available to physicians managing the care of the subjects.

Radiographs performed during follow up surgeon visits utilized at least two radiographic views, typically internal and external rotation views. The radiographs were assessed for imaging findings of AVN by the radiologist. Subjects were classified as having AVN if the humeral head demonstrated one or more of the following radiographic findings: a mixed lucent and sclerotic appearance, loss of sphericity and subchondral collapse (e.g., a "crescent sign"). If none of these findings were present during a 6-month follow-up examination the participant was coded as AVN negative for that visit.

\section{Histopathology}

In subjects who underwent arthroplasty the humeral head was analyzed for histopathologic evidence of

Table 1 CT acquisition parameters

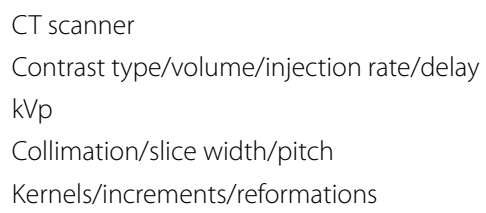

\author{
Somatom Definition Flash (Siemens Healthcare), dual source stellar detector \\ Omnipaque 350/120 ml/ $3 \mathrm{ml} / \mathrm{s} / 100 \mathrm{~s}$ \\ $100 \mathrm{kVp}$ and $140 \mathrm{kVp}$ \\ $128 \times 0.6 \mathrm{~mm} / 3 \mathrm{~mm} / 0.75$ \\ B30 (soft tissue) and B70 (bone)/3 mm/ bone and soft tissue axial, paracoro- \\ nal and parasagittal $3 \times 3 \mathrm{~mm}$ reformats using the mixed dataset
}


ischemia within $12 \mathrm{~h}$ of surgery. Upon gross evaluation of cartilage integrity and associated degenerative changes, the specimens were serially sectioned, in $3 \mathrm{~mm}$ thick slices, fixed in $10 \%$ buffered formalin for $12-24 \mathrm{~h}$ and decalcified using Decal solution (StatLab Medical Products, McKinney, TX). Sections were examined for presence of necrosis, thickened bone, or collapse of subchondral bone indicative of AVN. Microscopic parameters of ischemia were evaluated, including the presence of bone marrow necrosis and empty osteocytic lacunae. These findings were reported by the overall percentage of involvement. Based on the extent of ischemic change, the cases were classified as no ischemia, focal ischemia, or severe ischemia.

\section{Data analysis}

Because we were interested in testing feasibility of the methods, our study was not powered for detecting differences in DECT values between those who did and did not develop AVN. Rather, our study was powered to detect problems with recruitment and loss to follow-up [42]. A sample of 50 persons gave us greater than $95 \%$ confidence in detecting a $20 \%$ loss to follow-up and a $20 \%$ rate of decline in patient consent.

Reporting of the results of this prospective cohort study followed the STROBE guidelines [43]. We report the characteristics of our sample using descriptive statistics and we compared those with and those without follow-up data to assess differences in the two populations. Additionally, we compare the demographic and clinical characteristics of the treatment groups and subjects without and with AVN using one-way analysis of variance (ANOVA), the Fischer Exact Test Chi-square and the Independent T-test using $p \leq 0.05$ as a threshold for clinical significance and SAS software (SAS Institute Inc., Cary, NC, USA). Humerus iodine densities, glenoid iodine densities and humerus/glenoid iodine ratios for the three treatment categories are described and compared using ANOVA. Humerus iodine densities and humerus/glenoid iodine ratios in those with AVN and ischemia versus those without were described, but not statistically analyzed due to the low frequency of AVN.

\section{Results}

\section{Enrollment and management}

Sixty subjects provided informed written consent to participate in the study. Of these, 55 underwent a DECT scan (91.7\%). The other five subjects underwent conventional, single energy $\mathrm{CT}$ for treatment planning and were excluded from the study. Of the 55 subjects, $30.9 \%$ were treated conservatively, $38.2 \%$ underwent open reduction internal fixation (ORIF) and 30.9\% underwent arthroplasty (Table 2). The average age of subjects in
Table 2 Subject characteristics by treatment group

\begin{tabular}{|c|c|c|c|c|}
\hline \multirow[t]{2}{*}{ Characteristics } & \multicolumn{3}{|l|}{ Treatment } & \multirow[t]{2}{*}{$p$} \\
\hline & Arthroplasty & Conservative & ORIF & \\
\hline$n$ & 17 & 17 & 21 & - \\
\hline Age: Mean (SD) & $71(13)$ & $63(14)$ & $46(16)$ & $<0.001^{\mathrm{a}}$ \\
\hline Gender & $\begin{array}{l}14 \text { Female } \\
3 \text { Male }\end{array}$ & $\begin{array}{l}10 \text { Female } \\
7 \text { Male }\end{array}$ & $\begin{array}{l}6 \text { Female } \\
15 \text { Male }\end{array}$ & $0.003^{\mathrm{a}}$ \\
\hline Ethnicity & $\begin{array}{l}5 \text { Black } \\
1 \text { Asian } \\
11 \text { White }\end{array}$ & $\begin{array}{l}6 \text { Black } \\
11 \text { White }\end{array}$ & $\begin{array}{l}5 \text { Black } \\
16 \text { White }\end{array}$ & $N S^{a}$ \\
\hline \multicolumn{5}{|c|}{ lodine concentration mg/ml } \\
\hline Humerus (SD) & $3.97(0.70)$ & $3.97(0.97)$ & $4.78(1.22)$ & $0.022^{\mathrm{a}}$ \\
\hline Glenoid (SD) & $4.51(1.23)$ & $4.72(1.24)$ & $5.17(1.61)$ & $N S^{\mathrm{a}}$ \\
\hline $\begin{array}{l}\text { Humerus/glenoid } \\
\text { (SD) }\end{array}$ & $0.94(0.27)$ & $0.88(0.25)$ & $0.96(0.22)$ & $N S^{a}$ \\
\hline \multicolumn{5}{|l|}{ Follow up } \\
\hline 12 Months & & 8 & 12 & $N S^{b}$ \\
\hline 12 Months with AVN & & 0 & 2 & $N S^{b}$ \\
\hline 24 Months & & 4 & 10 & $N S^{b}$ \\
\hline 24 Months with AVN & & 0 & 3 & $N S^{b}$ \\
\hline \multicolumn{5}{|l|}{ Fracture healing } \\
\hline Healed $<12$ months & & 9 & 10 & $N S^{b}$ \\
\hline Healed $\leq 24$ months & & 9 & 13 & $N S^{b}$ \\
\hline
\end{tabular}

a One way ANOVA

${ }^{\mathrm{b}}$ Fischer Exact Test Chi-square

the conservative treatment group was 63 years (SD 14), 46 years in the ORIF group (SD 16) and 71 years (SD 13) in the arthroplasty group. 10 female subjects were managed conservatively, 6 managed with ORIF, and 14 with arthroplasty.

The 38 subjects who were treated conservatively or by ORIF were followed clinically and radiographically for the development of AVN. $52.6 \%$ of the subjects completed 12 months of follow up and $36.8 \%$ of these completed a total of 24 months of follow up (Table 2). Post-hoc analysis of the demographics of study and subjects lost to follow up at 12 and 24 months indicates similar genders, ethnicities, medical conditions and numbers with steroid treatment with a higher age of subjects lost to follow up compared to experimental subjects at 24 months (Table 3). While the number of subjects was small, post-hoc analysis demonstrated no differences in the frequency of subjects managed conservatively or by ORIF who were lost to follow up (Table 2).

\section{Fracture healing}

Of the 17 patients treated conservatively $59 \%$ had radiographs during at least one of the follow up appointments (Table 2). All but one of these subjects healed their proximal humerus fractures over the 24-month trial 
Table 3 Summary of comparisons between participants with and without follow-up data at 12 months and 24 months following recruitment

\begin{tabular}{|c|c|c|c|c|c|c|}
\hline \multirow[t]{2}{*}{ Characteristics } & \multicolumn{3}{|c|}{12 months } & \multicolumn{3}{|l|}{24 months } \\
\hline & Study & Lost & $p$ & Study & Lost & $p$ \\
\hline$n$ & 20 & 18 & & 14 & 24 & \\
\hline Age (SD) & $51(17.6)$ & $56(17.3)$ & $N S^{a}$ & $46.1(17.3)$ & $57.6(16.3)$ & $0.047^{\mathrm{a}}$ \\
\hline Male & 8 & 8 & $N S^{b}$ & 10 & 12 & $N S^{b}$ \\
\hline Female & 12 & 10 & & 4 & 12 & \\
\hline $\mathrm{AA}$ & 3 & 8 & $N S^{b}$ & 2 & 9 & $N S^{b}$ \\
\hline White & 17 & 10 & & 12 & 15 & \\
\hline Diabetes Mellitus & 4 & 3 & $N S^{b}$ & 1 & 6 & $N S^{b}$ \\
\hline Steroids & 1 & 0 & $N S^{b}$ & 1 & 0 & $N S^{b}$ \\
\hline
\end{tabular}

andependent T-test

${ }^{\mathrm{b}}$ Fischer Exact Test Chi-Square (2-sided)

period. The one subject who was incompletely healed at 6 months was lost to follow up.

Of the 21 subjects treated by ORIF, 71\% subjects had radiographs during at least one of the follow up appointments. Of these 15 subjects, two did not heal their fractures. One was followed over two years and developed AVN. Another did not demonstrate a healed fracture after 6 months and was subsequently lost to follow up.

\section{Rate of avascular necrosis}

Of the 20 subjects who had clinical and radiographic follow up for 12 months (Table 3), 10\% had radiographic evidence of AVN (Fig. 1g-h). Of the 14 subjects who completed 24 months of follow up, $21.4 \%$ developed AVN. All subjects who developed AVN underwent ORIF following the fracture. Differences between the subjects

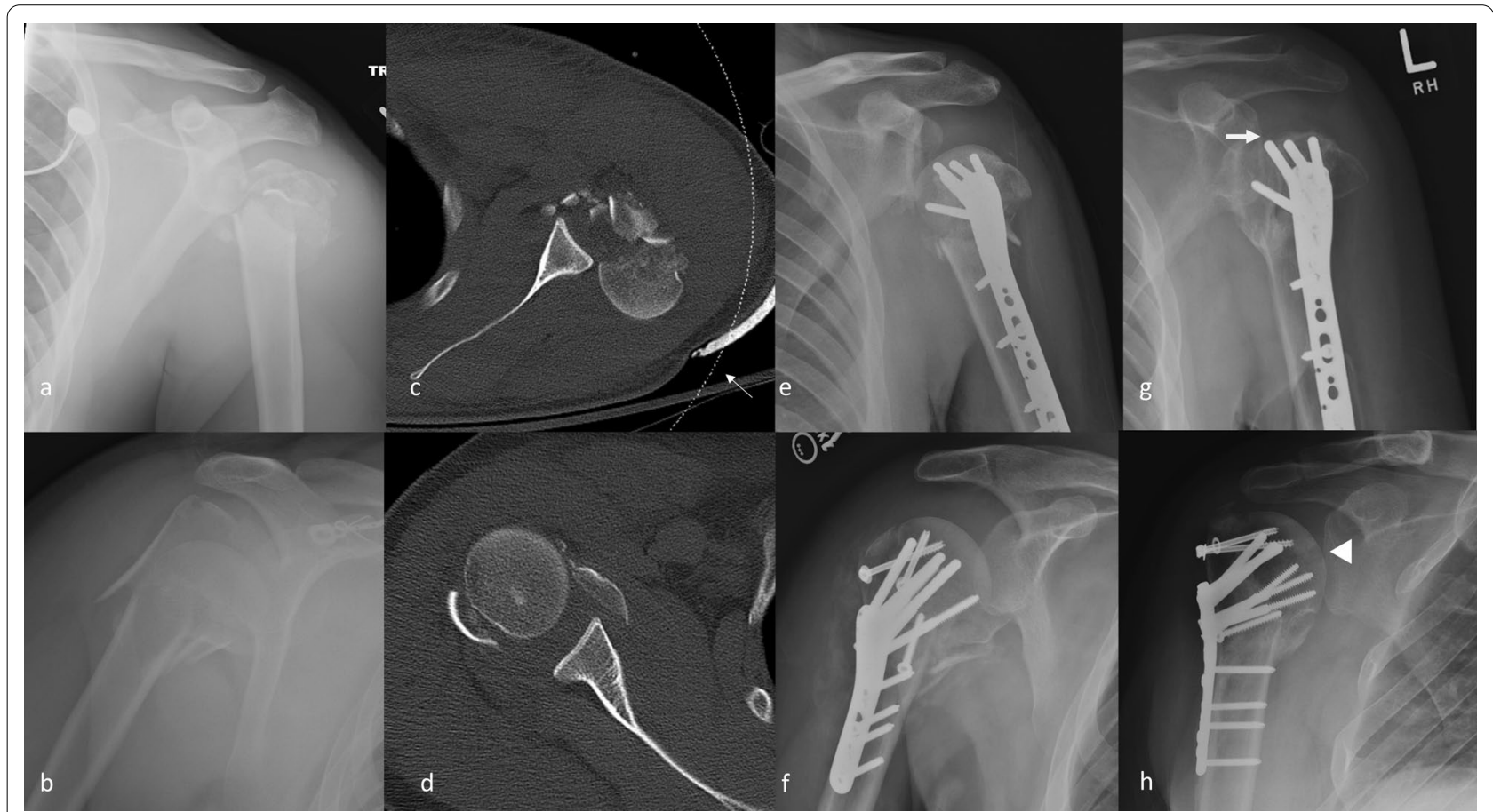

Fig. 1 Initial radiographic and CT images with follow up imaging demonstrating AVN. Images from a 26-year-old male (top row, a, c, e, $\mathbf{g}$ ) and a 36-year-old male $(\mathbf{b}, \mathbf{d}, \mathbf{f}, \mathbf{h})$ each with Neer four-part fractures were obtained including $\mathbf{a}, \mathbf{b}$ initial frontal radiograph, $\mathbf{c}, \mathbf{d}$ axial CT image, $\mathbf{e}, \mathbf{f}$ post-ORIF radiograph and $\mathbf{g}, \mathbf{h}$ evidence of osteonecrosis. $\mathbf{g}$ An attenuated linear shell of cortex with underlying lucency consistent with subchondral collapse due to AVN is present at 12 months after treatment (block arrow). $\mathbf{h}$ Subtle, circumscribed sclerosis adjacent to a focal lucency (block arrow) is consistent with AVN without collapse. The dashed line (c, thin arrow) indicates the outer margin of the $100 \mathrm{kVp}$ source 


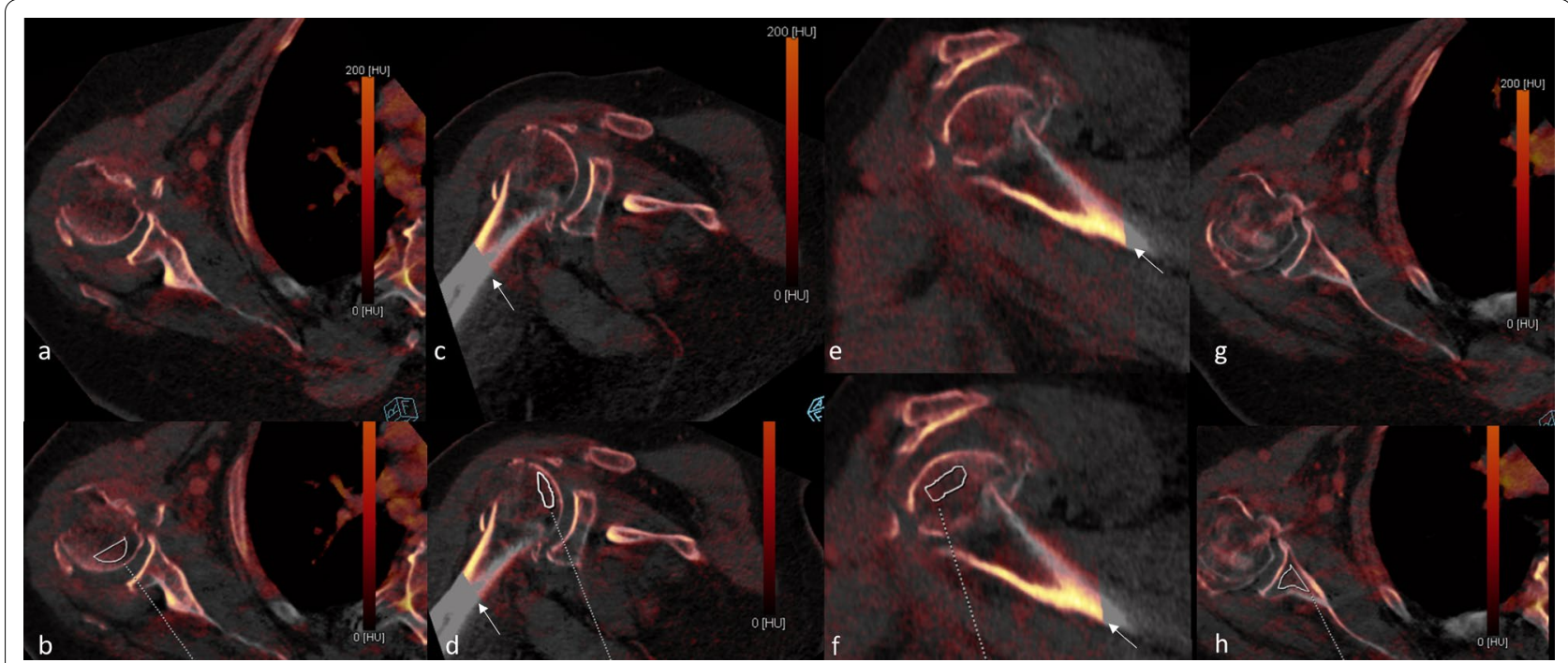

Fig. 2 lodine concentration measurements from DECT on an 86-year-old female subject with a Neer four-part proximal humerus fracture. The three planes of the right shoulder used for iodine concentration and humerus fragment measurements are shown: axial $(\mathbf{a}, \mathbf{b}, \mathbf{g}, \mathbf{h})$, coronal $(\mathbf{c}, \mathbf{d})$, sagittal $(\mathbf{e}, \mathbf{f})$. Areas were drawn in the humeral head fragment with overlying cartilage $(\mathbf{a}-\mathbf{f})$ and the glenoid vault $(\mathbf{g}, \mathbf{h})$ for iodine concentration measurement. The interfaces of the region with two energies (color, 100 and $140 \mathrm{kVp}$ ) and a single energy (no color, $140 \mathrm{kVp}$ ) is shown (thin arrows, c-f)

without and with AVN were not studied using statistics due to the low number of subjects with AVN (Table 2).

\section{lodine concentration and AVN}

Iodine concentration measures were higher, on average, in subjects with AVN compared to those without AVN (Fig. 2, Table 4). Because of the small sample size of persons with $\mathrm{AVN}$, results are described, but statistical significance was not evaluated. In the two subjects with AVN at 12 months, the average ratio of humeral head to glenoid iodine concentration (H/G ratio) was $15.4 \%$ higher in subjects with AVN. Iodine concentration in the humeral head was $20.2 \%$ higher in subjects with AVN. At 24 months, the $\mathrm{H} / \mathrm{G}$ ratio was $14.7 \%$ higher in those with AVN and the humeral head iodine concentration was $7.8 \%$ higher in those with AVN.

\section{Ischemia}

Humeral heads from 15 of 17 subjects who underwent shoulder arthroplasty underwent histopathologic analysis for parameters of ischemia (Table 5) [44-46]. The two subjects not analyzed either had only gross pathologic analysis or no pathology analysis. $46.7 \%$ of subjects had histopathologic evidence of ischemia (Table 5). Focal ischemia involving, on average, $20 \%$ of the tissue was identified in $33.3 \%$ of subjects. This presented as scattered areas of bone marrow necrosis associated with patchy empty osteocytic lacunae in the cortical bone.
Severe ischemia involving approximately $30 \%$ of the tissue was present in $13.3 \%$ of specimens.

The H/G ratios of subjects with severe ischemia and focal ischemia were $29.8 \%$ and $20.4 \%$ higher, respectively, than patients without ischemia (Table 5). The mean iodine concentration in subjects with severe ischemia and focal ischemia were $15.9 \%$ and $8.6 \%$ higher, respectively than those without ischemia. These values were not analyzed for statistical significance due to the small sample sizes.

\section{Discussion}

This feasibility study of 55 subjects monitored for AVN successfully followed $53 \%$ of subjects for 12 months and $37 \%$ for 24 months. AVN was identified exclusively in subjects who underwent ORIF. This suggests that postORIF subjects should be followed for 2 years, or more, in the future study of AVN. While difficult to know how the number of subjects lost to follow up biased the study results, bias is likely $[39,47]$.

The incidence of AVN in the literature varies widely depending on fracture comminution and displacement, treatment, and duration of clinical follow up [13]. An incidence as high as $75 \%$ has been reported for the most comminuted fractures with nonoperative treatment followed for at least 24 months [48]. Lower incidences of AVN have been reported for ORIF subjects treated with plate and screw construct fixation: $8 \%$ at 12 months of follow up and $20 \%$ at 60 months years of follow up [6-8], 
Table 4 Study parameters in subjects with and without AVN at 12 months and 24 months

\begin{tabular}{|c|c|c|c|c|}
\hline \multirow[t]{2}{*}{ lodine concentration $(\mathrm{mg} / \mathrm{ml})$} & \multicolumn{2}{|l|}{12 months } & \multicolumn{2}{|l|}{24 months } \\
\hline & $\begin{array}{l}\text { AVN } \\
(n=2)\end{array}$ & $\begin{array}{l}\text { No AVN } \\
(n=18)\end{array}$ & $\begin{array}{l}\text { AVN } \\
(n=3)\end{array}$ & $\begin{array}{l}\text { No AVN } \\
(n=11)\end{array}$ \\
\hline Humerus (SD) & $5.10(1.46)$ & $4.24(1.35)$ & $4.97(1.06)$ & $4.61(1.46)$ \\
\hline Glenoid (SD) & $4.82(0.31)$ & $4.87(1.76)$ & $4.66(.35)$ & $5.08(1.74)$ \\
\hline Humerus/glenoid (SD) & $1.05(0.24)$ & $0.91(0.24)$ & $1.06(0.17)$ & $0.92(0.21)$ \\
\hline
\end{tabular}

Comparison of means was not performed due to the low number of subjects

Table 5 Study parameters in subjects with and without focal ischemia and severe ischemia

\begin{tabular}{llll}
\hline lodine concentration $\mathbf{( m g / m l )}$ & $\begin{array}{l}\text { Focal ischemia } \\
(\mathbf{n}=\mathbf{5})\end{array}$ & $\begin{array}{l}\text { Severe ischemia } \\
(\mathbf{n = 2})\end{array}$ & $\begin{array}{l}\text { No ischemia } \\
(\mathbf{n}=\mathbf{8})\end{array}$ \\
\hline Humerus (SD) & $4.19(0.64)$ & $4.47(0.19)$ & $3.85(0.82)$ \\
Glenoid (SD) & $4.57(1.44)$ & $4.27(0.99)$ & $4.66(1.00)$ \\
Humerus/glenoid (SD) & $1.00(0.36)$ & $1.08(0.30)$ & $0.83(0.08)$ \\
\hline
\end{tabular}

Comparison of means was not performed due to the low number of subjects

which are similar to the $10 \%$ incidence at 12 months and $21.4 \%$ at 24 months in this study. An increase in incidence of AVN over time has previously been described in longitudinal studies comparing subjects at 12 months (4\% of subjects) and 45 months (9\%) and 35 months (26\%) to 84 months $(50 \%)[6,9]$. Unfortunately, there is no literature examining the histopathology of humerus fractures with which to compare our results.

Humerus to glenoid ratios of iodine concentration were elevated and similar in subjects with either AVN or ischemia at 12 and 24 months. While humeral head iodine concentrations were also elevated in AVN and ischemic subjects, they were higher at 12 months compared to 24 months. The similarity of the ratios at 12 and 24 months suggests this measurement may be more robust than the humerus iodine concentration alone.

Our results showing an increase in iodine concentration in AVN, and ischemia were the opposite of our initial hypothesis. This hypothesis was based on animal and human MRI studies of femoral neck fractures that showed a decrease in contrast enhancement including subjects who went on to develop AVN [18-22]. Animal studies indicate the disruption of arterial blood flow results in characteristic MRI changes and AVN. However, dynamic contrast enhanced MRI studies in subjects with atraumatic causes of AVN have demonstrated higher peak enhancement in femurs with AVN compared with normal adjacent bone and the normal contralateral femur [49-51]. The proposed mechanism for this relative increase in enhancement is vascular stasis due to venous outflow obstruction. Decreased venous outflow has been demonstrated in femoral head
AVN subjects using intraosseous venography: an early diagnostic tool in the functional exploration of bone to determine the risk of AVN [52]. Perhaps differences in blood flow to the humeral and femoral heads help explain the greater iodine concentration measured in subjects with AVN.

Compared to the femoral head, the humeral head receives blood supply from multiple vessels. The femoral head is almost exclusively vascularized by a single vessel: the extracapsular medial circumflex artery. Increasing femur fracture comminution, displacement, and capsule injury is more likely to injure this vessel and compromise blood flow [23, 53, 54]. In contrast, the humeral head is perfused by both the anterior and posterior humeral circumflex arteries with intraosseous anastomoses $[4,5]$. Specifically, in the area of the humeral head we measured, approximately $50 \%$ of blood flow is provided by each vessel [5]. Perhaps it is not arterial compromise that results in post-traumatic humerus AVN.

Time density analysis is an important next step to understand the reason for our results. Like the time intensity curves used in prior MRI studies, measurement of iodine density/concentration in humeral head fractures after contrast administration could confirm higher iodine concentration in subjects with AVN and elucidate the mechanism $[18,20-22,49,50]$. Additional measurements of the axillary artery and vein along with the humeral head of human subjects at discrete time intervals could be performed on human subjects, similar to the MRI time intensity curves and measurement of CT brain perfusion used to evaluate strokes $[55,56]$. 
This study has multiple strengths and weaknesses. One of the strengths was the novel and prospective use of CT technology. CT is already used routinely for the diagnosis of humerus fractures, but the use of IV contrast and dual energy CT to predict AVN has not been previously described. Conventional CT is hampered by the presence of calcium, which obscures the more subtle attenuation changes due to IV contrast. DECT allows the specific measurement of iodine concentration without the interference of calcium [33]. It also shows promise in determining tissue perfusion [28]. Recently, contrast enhanced DECT distinguished subjects with histopathologically proven AVN of the scaphoid bone from those without AVN [57]. In addition, contrast enhanced DECT was recently shown to detect enhancing bone metastasis, suggesting promise for the detection of areas of abnormal bone perfusion [58].

Another strength of this study was evaluation of compromised bone perfusion using two complementary techniques. Histopathologic evidence of early ischemia provides valuable early evidence of compromised perfusion. While less sensitive than other techniques in detection of AVN, radiographic evidence of AVN can provide specific evidence of decreased perfusion.

A significant weakness of this study was subject loss to follow up. The loss to follow up decreased the sample size and likely the number of subjects with AVN. The attrition of subjects was likely due to our reliance on clinical resources for follow up rather than the use of dedicated research coordinators and detailed follow up protocols and training [59]. Dedicated clinical research personnel is warranted in any future studies for better patient monitoring, communication and follow up. Another potential weakness was the use of radiography to determine the development of AVN. While this technique is not nearly as sensitive or specific as MRI or CT in the detection of AVN, it was chosen for multiple reasons. First, radiographs are routinely utilized in clinical settings to detect complications that warrant change in management, such as the identification of osteoarthritis that may indicate the need for shoulder arthroplasty. Second, while radiographs are relatively insensitive in detection of AVN, they allow excellent assessment of bone adjacent to hardware, such as collapse of the humeral head due to AVN and secondary osteoarthritis. This is clinically relevant, as patients with AVN may be asymptomatic [5]. MRI in the presence of hardware requires optimization including the use of time and expertise intensive protocols that have not been well described in the humerus [60]. Finally, radiography is relatively inexpensive compared to MRI, which was an important consideration for this pilot study.
Our feasibility study was designed, not for generalizability, but rather to inform the design of a larger study. If our DECT measures are representative, a two-group t-test with a $5 \%$ two-sided significance level will have $80 \%$ power to detect the difference between subjects without AVN (mean H/G ratio 0.92) from those who develop AVN (1.06) with a sample size of 106 subjects treated conservatively or with ORIF assuming a $20 \%$ incidence of AVN at two years. Fewer subjects might be necessary if follow-up is extended out to five years to increase the proportion of participants with AVN $[6,9]$. While the role of ORIF in the development of AVN is controversial, based on our finding that only subjects treated with ORIF developed AVN, prospectively studying ORIF subjects may also decrease the total number of subjects required. The use of dedicated research staff to monitor subjects will be essential to reduce loss to follow up. Finally, the use of time concentration analysis in the next study of DECT will enhance our understanding of how iodine concentration may serve as an indicator of AVN risk in humeral head fractures.

\section{Conclusions}

This feasibility study demonstrated the ability to successfully perform DECT with contrast on patients with humeral head fractures and provides useful baseline information to inform a larger study of the test to predict AVN. Further investigation of contrast enhanced DECT will better define its promise to predict those at increased risk of developing AVN.

\section{Abbreviations}

ANOVA: Analysis of variance; AVN: Avascular necrosis; CT: Computed tomography; DECT: Dual energy computed tomography; IV: Intravenous; MRI: Magnetic resonance imaging; ORIF: Open reduction internal fixation.

\section{Acknowledgements \\ Not applicable.}

\section{Authors' contributions}

$\mathrm{KBH}$ designed the work, was directly involved in data acquisition and analysis, interpretation of data, drafting of the work, approval of the submitted version and agrees both to be personally accountable for her contributions and ensures that questions related to the accuracy or integrity of any part of the work are appropriately investigated, resolved, and the resolution documented in the literature. AOS made substantial contributions to the acquisition, analysis and interpretation of data, substantively revised the manuscript, approved the submitted version and agrees both to be personally accountable for her contributions and ensures that questions related to the accuracy or integrity of any part of the work are appropriately investigated, resolved, and the resolution documented in the literature. VR made substantial contributions to the acquisition, analysis, and interpretation of data. substantively revised the manuscript, approved the submitted version and agrees both to be personally accountable for her contributions and ensures that questions related to the accuracy or integrity of any part of the work are appropriately investigated, resolved, and the resolution documented in the literature. DLR VR made substantial contributions to the acquisition, analysis, and interpretation of data. substantively revised the manuscript, approved the submitted version and agrees both to be personally accountable for her contributions and 
ensures that questions related to the accuracy or integrity of any part of the work are appropriately investigated, resolved, and the resolution documented in the literature. All authors read and approved the final manuscript.

\section{Funding}

No funding was provided for this study.

\section{Availability of data and materials}

The datasets used and/or analyzed during the current study are available from the corresponding author on request.

\section{Declarations}

\section{Ethics approval and consent to participate}

This Virginia Commonwealth University Institutional Review Board (IRB) approved study (IRB HM20000037_CR6 Computed Tomography Evaluation of Humeral Head Perfusion in Displaced Proximal Humerus Fractures in Predicting Rates of Avascular Necrosis) received written patient consent from all study subjects.

\section{Consent for publication}

Not applicable.

\section{Competing interests}

The authors declare that they have no competing interests.

\section{Author details}

${ }^{1}$ Mink Radiology, Cedars-Sinai Health System, 8670 Wilshire Blvd Suite 101, Beverly Hills, CA 90211, USA. ${ }^{2}$ Orthopedic Associates of Lancaster, 170 North Pointe Blvd, Lancaster, PA 17601, USA. ${ }^{3}$ Department of Pathology, Virginia Commonwealth University/VCU Health, 1101 East Marshall St, P.O. Box 980662 Richmond, VA 23298-0662, USA. ${ }^{4}$ Otto D. Payton Professor of Physical Therapy, Orthopaedic Surgery and Rheumatology, Virginia Commonwealth University, Room B-100, West Hospital, 1200 East Broad Street, Richmond, VA 23298, USA.

Received: 13 July 2020 Accepted: 25 November 2021

Published online: 11 December 2021

\section{References}

1. Mauro CS. Proximal humeral fractures. Curr Rev Musculoskelet Med. 2011;4(4):214-20.

2. Court-Brown CM, Caesar B. Epidemiology of adult fractures: a review. Injury. 2006;37(8):691-7.

3. Neer CS 2nd. Displaced proximal humeral fractures. I. Classification and evaluation. J Bone Joint Surg Am. 1970;52(6):1077-89.

4. Brooks $\mathrm{CH}$, Revell WJ, Heatley FW. Vascularity of the humeral head after proximal humeral fractures. An anatomical cadaver study. J Bone Joint Surg Br. 1993;75(1):132-6.

5. Hettrich CM, Boraiah S, Dyke JP, Neviaser A, Helfet DL, Lorich DG. Quantitative assessment of the vascularity of the proximal part of the humerus. J Bone Joint Surg Am. 2010;92(4):943-8.

6. Greiner S, Kaab MJ, Haas NP, Bail HJ. Humeral head necrosis rate at midterm follow-up after open reduction and angular stable plate fixation for proximal humeral fractures. Injury. 2009;40(2):186-91.

7. Bastian JD, Hertel R. Initial post-fracture humeral head ischemia does not predict development of necrosis. J Shoulder Elbow Surg. 2008;17(1):2-8.

8. Brunner F, Sommer C, Bahrs C, Heuwinkel R, Hafner C, Rillmann P, Kohut G, Ekelund A, Muller M, Audige $L$, et al. Open reduction and internal fixation of proximal humerus fractures using a proximal humeral locked plate: a prospective multicenter analysis. J Orthop Trauma. 2009;23(3):163-72.

9. Harrison AK, Gruson KI, Zmistowski B, Keener J, Galatz L, Williams G, Parsons BO, Flatow EL. Intermediate outcomes following percutaneous fixation of proximal humeral fractures. J Bone Joint Surg Am. 2012;94(13):1223-8

10. Murray IR, Amin AK, White TO, Robinson CM. Proximal humeral fractures: current concepts in classification, treatment and outcomes. J Bone Joint Surg Br. 2011;93(1):1-11.
11. Poeze M, Lenssen AF, Van Empel JM, Verbruggen JP. Conservative management of proximal humeral fractures: can poor functional outcome be related to standard transscapular radiographic evaluation? J Shoulder Elb Surg/Am Shoulder Elb Surg [et al]. 2010;19(2):273-81.

12. Tejwani NC, Liporace F, Walsh M, France MA, Zuckerman JD, Egol KA. Functional outcome following one-part proximal humeral fractures: a prospective study. J Shoulder Elb Surg/Am Shoulder Elb Surg [et al]. 2008;17(2):216-9.

13. Patel S, Colaco HB, Elvey ME, Lee MH. Post-traumatic osteonecrosis of the proximal humerus. Injury. 2015;46(10):1878-84.

14. Muller ME. Appendix A. In: Allgöwer M, editor. Manual of internal fixation: techniques recommended by the AO-ASIF Group. Berlin: Springer; 1991. p. $118-25$.

15. Boileau P, Pennington SD, Alami G. Proximal humeral fractures in younger patients: fixation techniques and arthroplasty. Am Acad Orthop Surg Spec Issue. 2011;20(2, Supplement):S47-60.

16. Nho SJ, Brophy RH, Barker JU, Cornell CN, MacGillivray JD. Innovations in the management of displaced proximal humerus fractures. J Am Acad Orthop Surg. 2007;15(1):12-26.

17. Hertel R, Hempfing A, Stiehler M, Leunig M. Predictors of humeral head ischemia after intracapsular fracture of the proximal humerus. J Shoulder Elb Surg/Am Shoulder Elb Surg [et al]. 2004;13(4):427-33.

18. Kamano M, Narita S, Honda Y, Fukushima K, Yamano Y. Contrast enhanced magnetic resonance imaging for femoral neck fracture. Clin Orthop Relat Res. 1998;350:179-86.

19. Hirata T, Konishiike T, Kawai A. Dynamic magnetic resonance imaging of femoral head perfusion in femoral neck fracture. Clin Orthop Relat Res. 2001;393:294-301.

20. Konishiike T, Makihata $E$, Tago H, Sato T, Inoue H. Acute fracture of the neck of the femur. An assessment of perfusion of the head by dynamic MRI. J Bone Joint Surg Br. 1999:81(4):596-9.

21. Cova M, Kang YS, Tsukamoto H, Jones LC, McVeigh E, Neff BL, Herold CJ, Scott WW Jr, Hungerford DS, Zerhouni EA. Bone marrow perfusion evaluated with gadolinium-enhanced dynamic fast MR imaging in a dog model. Radiology. 1991;179(2):535-9.

22. Nadel SN, Debatin JF, Richardson WJ, Hedlund LW, Senft C, Rizk WS, Malizos KN, Stahl DL, Martinez S. Detection of acute avascular necrosis of the femoral head in dogs: dynamic contrast-enhanced MR imaging vs spinecho and STIR sequences. AJR Am J Roentgenol. 1992;159(6):1255-61.

23. Ehlinger M, Moser T, Adam P, Bierry G, Gangi A, de Mathelin M, Bonnomet F. Early prediction of femoral head avascular necrosis following neck fracture. Orthopaed Traumatol Surg Res OTSR. 2011;97(1):79-88.

24. Baffour FI, Glazebrook KN, Morris JM, Michalak GJ, Fletcher JG, Leng S, McCollough CH. Clinical utility of virtual noncalcium dual-energy CT in imaging of the pelvis and hip. Skeletal Radiol. 2019;48(12):1833-42.

25. Heye T, Nelson RC, Ho LM, Marin D, Boll DT. Dual-energy CT applications in the abdomen. AJR Am J Roentgenol. 2012;199(5 Suppl):S64-70.

26. Johnson TR. Dual-energy CT: general principles. AJR Am J Roentgenol. 2012;199(5 Suppl):S3-8.

27. Song KD, Kim CK, Park BK, Kim B. Utility of iodine overlay technique and virtual unenhanced images for the characterization of renal masses by dual-energy CT. AJR Am J Roentgenol. 2011;197(6):W1076-1082.

28. Skornitzke S, Fritz F, Mayer P, Koell M, Hansen J, Pahn G, Hackert T, Kauczor HU, Stiller W. Dual-energy CT iodine maps as an alternative quantitative imaging biomarker to abdominal CT perfusion: determination of appropriate trigger delays for acquisition using bolus tracking. Br J Radiol. 2018;91(1085):20170351.

29. Hawkes DJ, Jackson DF, Parker RP. Tissue analysis by dual-energy computed tomography. Br J Radiol. 1986;59(702):537-42.

30. Fletcher JG, Takahashi N, Hartman R, Guimaraes L, Huprich JE, Hough DM, Yu L, McCollough CH. Dual-energy and dual-source CT: is there a role in the abdomen and pelvis? Radiol Clin N Am. 2009;47(1):41-57.

31. Nickoloff EL, Feldman F, Atherton JV. Bone mineral assessment: new dualenergy CT approach. Radiology. 1988;168(1):223-8.

32. Rosenthal DI, Hayes CW, Rosen B, Mayo-Smith W, Goodsitt MM. Fatty replacement of spinal bone marrow due to radiation: demonstration by dual energy quantitative CT and MR imaging. J Comput Assist Tomogr. 1989;13(3):463-5.

33. Tran DN, Straka M, Roos JE, Napel S, Fleischmann D. Dual-energy CT discrimination of iodine and calcium: experimental results and implications for lower extremity CT angiography. Acad Radiol. 2009;16(2):160-71. 
34. Takai M, Kaneko M. Discrimination between thorotrast and iodine contrast medium by means of dual-energy CT scanning. Phys Med Biol. 1984;29(8):959-67.

35. Graser A, Johnson TR, Chandarana H, Macari M. Dual energy CT: preliminary observations and potential clinical applications in the abdomen. Eur Radiol. 2009;19(1):13-23.

36. Baxa J, Matouskova T, Krakorova G, Schmidt B, Flohr T, Sedlmair M, Bejcek J, Ferda J. Dual-phase dual-energy CT in patients treated with erlotinib for advanced non-small cell lung cancer: possible benefits of iodine quantification in response assessment. Eur Radiol. 2016;26(8):2828-36.

37. Hellbach K, Sterzik A, Sommer W, Karpitschka M, Hummel N, Casuscelli J, Ingrisch M, Schlemmer M, Graser A, Staehler M. Dual energy CT allows for improved characterization of response to antiangiogenic treatment in patients with metastatic renal cell cancer. Eur Radiol. 2017;27(6):2532-7.

38. Thabane L, Ma J, Chu R, Cheng J, Ismaila A, Rios LP, Robson R, Thabane M, Giangregorio L, Goldsmith $\mathrm{CH}$. A tutorial on pilot studies: the what, why and how. BMC Med Res Methodol. 2010;10:1.

39. Dumville JC, Torgerson DJ, Hewitt CE. Reporting attrition in randomised controlled trials. BMJ. 2006;332(7547):969-71.

40. Boutin RD, Kaptuch JM, Bateni CP, Chalfant JS, Yao L. Influence of IV contrast administration on CT measures of muscle and bone attenuation: implications for sarcopenia and osteoporosis evaluation. AJR Am J Roentgenol. 2016;207(5):1046-54.

41. Bae KT. Intravenous contrast medium administration and scan timing at CT: considerations and approaches. Radiology. 2010;256(1):32-61.

42. Viechtbauer W, Smits L, Kotz D, Bude L, Spigt M, Serroyen J, Crutzen R. A simple formula for the calculation of sample size in pilot studies. J Clin Epidemiol. 2015;68(11):1375-9.

43. von Elm E, Altman DG, Egger M, Pocock SJ, Gøtzsche PC, Vandenbroucke JP. The strengthening the reporting of observational studies in epidemiology (STROBE) statement: guidelines for reporting observational studies. Lancet. 2007;370(9596):1453-7.

44. Fondi C, Franchi A. Definition of bone necrosis by the pathologist. Clin Cases Miner Bone Metab Off J Ital Soc Osteoporos Miner Metab Skelet Dis. 2007:4(1):21-6.

45. Cruess RL. Osteonecrosis of bone. Current concepts as to etiology and pathogenesis. Clin Orthop Relat Res. 1986;208:30-9.

46. Catto M. A histological study of avascular necrosis of the femoral head after transcervical fracture. J Bone Joint Surg Br. 1965;47(4):749-76.

47. Fewtrell MS, Kennedy K, Singhal A, Martin RM, Ness A, Hadders-Algra $M$, Koletzko B, Lucas A. How much loss to follow-up is acceptable in long-term randomised trials and prospective studies? Arch Dis Child. 2008;93(6):458-61.

48. Leyshon RL. Closed treatment of fractures of the proximal humerus. Acta Orthop Scand. 1984;55(1):48-51.

49. Chan WP, Liu Y-J, Huang G-S, Lin M-F, Huang S, Chang Y-C, Jiang C-C. Relationship of idiopathic osteonecrosis of the femoral head to perfusion changes in the proximal femur by dynamic contrast-enhanced MRI. Am J Roentgenol. 2011;196(3):637-43.

50. Lee JH, Dyke JP, Ballon D, Ciombor DM, Tung G, Aaron RK. Assessment of bone perfusion with contrast-enhanced magnetic resonance imaging. Orthop Clin N Am. 2009;40(2):249-57.

51. Bluemke DA, Petri M, Zerhouni EA. Femoral head perfusion and composition: MR imaging and spectroscopic evaluation of patients with systemic lupus erythematosus and at risk for avascular necrosis. Radiology. 1995;197(2):433-8.

52. Ficat RP. Idiopathic bone necrosis of the femoral head. Early diagnosis and treatment. J Bone Joint Surg Br. 1985;67(1):3-9.

53. Trueta J, Harrison MH. The normal vascular anatomy of the femoral head in adult man. J Bone Joint Surg Br. 1953;35-b(3):442-61.

54. Boraiah S, Dyke JP, Hettrich C, Parker RJ, Miller A, Helfet D, Lorich D. Assessment of vascularity of the femoral head using gadolinium (GdDTPA)-enhanced magnetic resonance imaging: a cadaver study. J Bone Joint Surg Br. 2009;91(1):131-7.

55. Konstas AA, Goldmakher GV, Lee TY, Lev MH. Theoretic basis and technical implementations of $C T$ perfusion in acute ischemic stroke, part 2: technical implementations. AJNR Am J Neuroradiol. 2009;30(5):885-92.

56. Fan M, Peng J, Qin L, Lu S. Experimental animal models of osteonecrosis. Rheumatol Int. 2011;31(8):983-94.
57. Pianta M, McCombe D, Slavin J, Hendry S, Perera W. Dual-energy contrastenhanced CT to evaluate scaphoid osteonecrosis with surgical correlation. J Med Imaging Radiat Oncol. 2019;63(1):69-75.

58. Lee YH, Kim S, Lim D, Suh JS, Song HT. Spectral parametric segmentation of contrast-enhanced dual-energy CT to detect bone metastasis: feasibility sensitivity study using whole-body bone scintigraphy. Acta Radiol (Stockholm, Sweden:1987). 2015;56(4):458-64.

59. Abshire M, Dinglas VD, Cajita MI, Eakin MN, Needham DM, Himmelfarb CD. Participant retention practices in longitudinal clinical research studies with high retention rates. BMC Med Res Methodol. 2017;17(1):30.

60. Farshad-Amacker NA, Koff MF, Dyke JP, Lazaro LE, Shah P, Lorich DG, Potter $\mathrm{HG}$. Assessment of osteonecrosis in the presence of instrumentation for femoral neck fracture using contrast-enhanced MAVRIC sequence. HSS J Musculoskelet J Hosp Spec Surg. 2016;12(1):51-8.

\section{Publisher's Note}

Springer Nature remains neutral with regard to jurisdictional claims in published maps and institutional affiliations.
Ready to submit your research? Choose BMC and benefit from:

- fast, convenient online submission

- thorough peer review by experienced researchers in your field

- rapid publication on acceptance

- support for research data, including large and complex data types

- gold Open Access which fosters wider collaboration and increased citations

- maximum visibility for your research: over 100M website views per year

At BMC, research is always in progress.

Learn more biomedcentral.com/submissions 